\title{
The role of phonological awareness in reading comprehension
}

\author{
Maria Silvia Cárnio(1) \\ Jéssica Sales Vosgrau (1) \\ Aparecido José Couto Soares ${ }^{(1)}$
}

(1) Faculdade de Medicina da Universidade de São Paulo - São Paulo - SP - Brazil. Project developed at the Laboratório de Investigação Fonoaudiológica em Leitura e Escrita.

Research support source: Fundação de Amparo à Pesquisa e Ensino do Estado de São Paulo (FAPESP).

Conflict of interest: Nonexistent

Received on: December 15, 2016 Accepted on: July 20, 2017

Mailing address:

Aparecido José Couto Soares

Universidade de São Paulo - Departamento de Fisioterapia, Fonoaudiologia e Terapia Ocupacional

Rua Cipotanea, 51 - São Paulo, São Paulo, Brasil

CEP: 05360-000

E-mail: ajcsoares@usp.br

\section{ABSTRACT}

Purpose: to characterize the performance of 4th grade-Elementary School students with and without signs of reading and writing disorders as for phonological awareness and reading comprehension, and also verify possible correlations between them.

Methods: 60 children enrolled in the 4th grade of Elementary School from two public schools, whose parents signed the Informed Consent Form, participated in the present study. They were selected and organized in groups, with and without signs of reading and writing disorders. All students were individually assessed regarding their phonological awareness and reading comprehension of sentences and texts through standardized tests. The data underwent statistical analysis.

Results: those with signs of reading and writing disorders showed the lowest performance in the reading comprehension of sentences and texts. A correlation was found between phonological awareness and reading comprehension of sentences and texts in both groups.

Conclusion: students with no signs of reading and writing disorders had a higher performance in the skills assessed. The correlation found between phonological awareness and reading comprehension of sentences and texts shows not only the importance of metaphonological skills for a proficient reading, but also for a comprehensive one.

Keywords: Evaluation; Reading; Comprehension; Education; Learning 


\section{INTRODUCTION}

Phonological awareness (PA) is a metalinguistic skill characterized by the ability to perceive that speech can be segmented into words, syllables, and phonemes and that these can be consciously manipulated by the individual ${ }^{1-5}$. It forms part of phonological processing, and there is extensive evidence that the skills that compose it are necessary for learning how to read and write $^{3,6-8}$.

PA involves syllabic and phonemic skills. It is known that syllabic skills precede and develop more easily than phonemic skills because they are an early stage of recognition and manipulation of a language's sound structure ${ }^{4,9-11}$. However, syllabic skills are fundamental for the development of phonemics, which is more effective for learning to read and write ${ }^{12}$.

On the other hand, reading comprehension $(\mathrm{RC})$ is a cognitive process, which encompasses decoding up to the extraction of the meaning of the material being read, and is considered by some authors as the basic purpose of learning how to read ${ }^{10,13}$. Thus, reading comprehension involves, besides decoding, the participation of many cognitive processes-memory, acquired vocabulary, fluency, and inference - that allow the construction of meanings, leading to the comprehension of the material being read ${ }^{14-16}$.

The relationship between PA and reading has been widely investigated in the literature, but most of the studies have focused on understanding the relationship between phonological awareness and decoding, accuracy, and reading fluency of words and pseudowords $2,10,11,17$. Thus, it is necessary to investigate the knowledge of PA more deeply to determine whether its influence encompasses not only the aspects related to decoding efficiency and quality, but also reading comprehension. The results of this study will contribute relevantly to the field of written reading by investigating possible correlations between phonological awareness and sentence (SRC) and text (TRC) reading comprehension.

This study aimed to characterize the performance of $4^{\text {th }}$-grade elementary school (ES) children with and without indications of reading and writing disorders on PA, SRC, and TRC, and to verify possible correlations between these skills.

\section{METHODS}

This research was approved by the University of São Paulo Ethics Committee - USP under the number
097/13. The data was collected in two São Paulo state schools. Sixty fourth-grade children in elementary school whose parents and teachers signed the Informed Consent Form participated in this study, and their average age was 9.6 years old.

\section{Selection of participants}

To select the subjects of this study without indications of reading and writing disorders, the following inclusion criteria were adopted: Regular enrollment in the fourth year of elementary school; approval of the parents and/or guardians through signature of the Informed Consent Form; absence of complaints or indications regarding hearing, vision, neurological, behavioral, or cognitive disorders, verified through the recommendation of teachers who have attested the absence of such claims from themselves and their parents in the school chart; and average or above average scores on the School Performance Test $(\mathrm{SPT})^{18}$. Membership in the group with indications of reading and writing disorders was determined by applying all the criteria listed except for the SPT score, which in this case should be below the expected score for a child that age. Note that the choice of fourth graders as the target group of this study is due to the fact that by that year of school most children already possess a set of basic decoding skills, and as shown by many studies their cognitive and metacognitive skills are more available for the complex process of reading comprehension, one of the variables investigated in this project.

Due to the difficulties encountered in returning the Informed Consent Form - Parents/Guardians (ICF) in the school where the study was first performed (hereby referred to as school A), the study was also performed on students of another school, hereafter referred to as school B. At school A, a total of 38 subjects met all inclusion criteria, while 22 students at school B met all the inclusion criteria and were part of the research sample, totaling 60 students. Both schools belonged to the region where the study was conducted and use the social constructivist method of literacy conception.

All children underwent reading and writing evaluation through the SPT, which is divided into three parts: word dictation (maximum score $=34$ ), arithmetic (maximum score $=38$ ), and reading isolated words (maximum score $=70$ ). For each correct answer the child gets one point, and the total score is 142 points; the average score for the $4^{\text {th }}$ graders is 102 to 112 points. 
Thus, subjects with lower performance were part of the group with indications of reading and writing disorders (GWI) and those with an average and above average scores were part of the group without indications of reading and writing disorders (GWOI). The sample was divided into four groups:

1. The group without indications of reading and writing disorders (GWOI) from School A - 17 children, 9 male $(52.9 \%)$ and 8 female (47\%), with an average age of 9 years and 4 months;

2. The group with indications of reading and writing disorders (GWI) from School A - 21 children, 10 male (47.6\%) and 11 female (52.3\%), with an average age of 9 years and 2 months;

3. The group without indications of reading and writing disorders (GWOI) from School B - 13 children, 6 male (46\%) and 7 female (53.8\%), with an average age of 9 years and 9 months;

4. The group with indications of reading and writing disorders (GWI) from School B - 9 children, 6 male $(66.6 \%)$ and 3 female (33.3\%), with an average age of 10 years.

\section{Experimental Tests}

The subjects were individually evaluated for SRC, TRC, and PA, following the application and scoring instructions described on the tests used.

The subjects underwent the SRC and TRC tests, numbers 9 and 10 of Item IV in the PROLEC Test ${ }^{19}$. The PROLEC Sentences (PROLEC-S) consists of 12 sentences that express simple orders. The established average score for $4^{\text {th }}$ grade ES children is $\geq 11.80$ points. The PROLEC Texts (PROLEC-T) is composed of four small texts (two narrative texts and two lecture texts) whose meaning must be extracted to answer the four oral questions of each text. The established average score for $4^{\text {th }}$ grade ES children is $\geq 13.78$ points.

For the PA evaluation, the CONFIAS - Phonological Awareness: Instrument for Sequential Evaluation ${ }^{20}$ was used, which contains a total of 70 items that the child must answer regarding synthesis, segmentation, rhymes, alliteration, initial and final syllable identification, and syllable and phoneme transposition. The average score for each child is assigned through the hypothesis of writing.

\section{Procedures for statistical analysis of the results}

The chi-square test was used to compare the percentage of children from both schools.

The Kruskal-Wallis test was applied to compare the score distribution of the teachers' questionnaire and of the PROLEC-S, PROLECT-T, and CONFIAS for the GWI and GWOI.

The Spearman correlation coefficient was calculated to measure the correlation between PROLEC-T and PROLEC-S and the correlation between the PROLEC (Sentences and Texts) and the CONFIAS.

A ROC curve was built to analyze the CONFIAS, considering the PROLEC-T as the gold standard.

On the hypothesis tests, the significance level was fixed at 0.05 .

\section{RESULTS}

The descriptive analysis of PROLEC-S performance showed that at School B most individuals from the GWI and GWOI were classified as above average, while at School A that was only true of the GWOI (Table 1).

As for the PROLEC-T results, the school of origin was not considered, since there was no significant difference (GWI: $p=0.464$; GWOI: $p=0.108$ ) between the score distributions of both schools; therefore, the analysis of the results of this test will be considered only by group (GWI and GWOI). It was observed that most of the GWI children were classified as "below average," while most of the GWOI children fell in the "above average" category (Table 2). 
Table 1. Frequency and percentage distributions of the PROLEC Sentence Classification in the groups with and without indications of reading and writing disorders

\begin{tabular}{ccccc}
\hline \multirow{2}{*}{ Group } & \multicolumn{2}{c}{ PROLEC Sentence Classification } & \multirow{2}{*}{ Total } \\
\cline { 2 - 4 } & Below Average & Average & Above Average & \\
\cline { 2 - 4 } With indications -School A & 11 & 9 & 1 & 21 \\
Without Indications - School A & $52.4 \%$ & $42.9 \%$ & $4.8 \%$ & $100.0 \%$ \\
& 1 & 3 & 13 & 17 \\
Total & $5.9 \%$ & $17.6 \%$ & $76.5 \%$ & $100.0 \%$ \\
& 12 & 12 & 14 & 38 \\
With indications - School B & $31.6 \%$ & $21.6 \%$ & $36.8 \%$ & $100.0 \%$ \\
\hline \multirow{2}{*}{ Without Indications - School B } & 2 & $22.2 \%$ & $55.6 \%$ & 9 \\
& $22.2 \%$ & 0 & 13 & $100.0 \%$ \\
Total & 0 & $0.0 \%$ & $100.0 \%$ & 13 \\
& $0.0 \%$ & 2 & 18 & $100.0 \%$ \\
& 2 & $9.1 \%$ & $81.8 \%$ & 22 \\
& $9.1 \%$ & & $100.0 \%$ \\
\hline
\end{tabular}

Table 2. Descriptive summary of the PROLEC Text score between groups with and without indications of reading and writing disorders per school

\begin{tabular}{cccccccc}
\hline \multicolumn{1}{c}{ Group } & School & N & Average & $\begin{array}{c}\text { Standard } \\
\text { Deviation }\end{array}$ & Minimum & Median & Maximum \\
\hline \multirow{3}{*}{ With indications } & SCHOOL A & 21 & 7.9 & 4,9 & 0 & 9 & 16 \\
& SCHOOL B & 9 & 12.0 & 1,7 & 9 & 13 & 14 \\
& Total & 30 & 9.1 & 4,6 & 0 & 10 & 16 \\
\hline \multirow{3}{*}{ Without Indications } & SCHOOL A & 17 & 13.7 & 1,5 & 11 & 14 & 16 \\
& SCHOOL B & 13 & 14.2 & 1,4 & 11 & 15 & 16 \\
& Total & 30 & 13.9 & 1,5 & 11 & 14 & 16 \\
\hline
\end{tabular}

Table 3. Distribution of frequencies and percentages of the PROLEC text classification in groups with and without indications of reading and writing disorders

\begin{tabular}{|c|c|c|c|c|}
\hline \multirow{2}{*}{ Groups } & \multicolumn{3}{|c|}{ PROLEC Text Classification } & \multirow{2}{*}{ Total } \\
\hline & Below Average & Average & Above Average & \\
\hline \multirow[t]{2}{*}{ GWI } & 22 & 4 & 4 & 30 \\
\hline & $73.3 \%$ & $13.3 \%$ & $13.3 \%$ & $100.0 \%$ \\
\hline \multirow[t]{2}{*}{ GWOI } & 7 & 5 & 18 & 30 \\
\hline & $23.3 \%$ & $16.7 \%$ & $60.0 \%$ & $100.0 \%$ \\
\hline \multirow[t]{2}{*}{ Total } & 29 & 9 & 22 & 60 \\
\hline & $48.3 \%$ & $15.0 \%$ & $36.7 \%$ & $100.0 \%$ \\
\hline
\end{tabular}

Legend: GWI - group with indications of reading and writing disorders; GWOI: group without indications of reading and writing disorders 
There was also no significant difference $(p>0.999)$ between the schools on the CONFIAS, and so the children were analyzed only by the group divisions (GWI and GWOI). The GWOI results were better than those of the GWI when it came to syllables, phonemes, and total results, with a statistically significant difference $(p<0.001)$ (Figure 1).

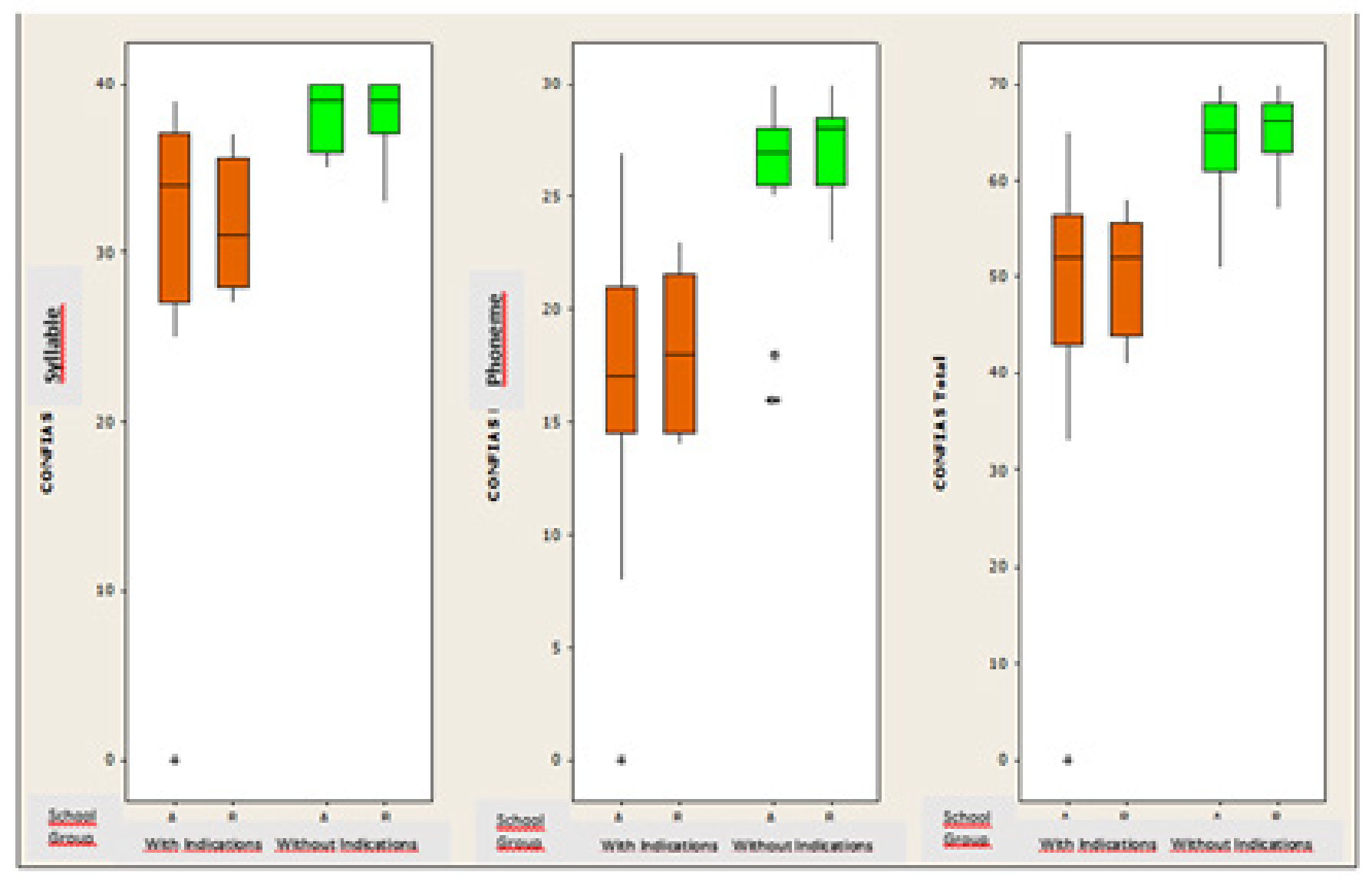

Figure 1. Box-plots of the CONFIAS Syllable, Phoneme, and Total of the groups with and without indications of reading and writing disorders per school

The scatter plot illustrates that the correlation between SRC and TRC for the GWI was significant (Figure 2). The value of the Spearman correlation coefficient for the PROLEC-T and PROLEC-S scores was $r$ $=0.67(p<0.001)$, while for the group without indications, the coefficient value was $r=0.25(p=0.118)$.

As for the correlation between SRC and the CONFIAS (syllable, phoneme, and total), the scatter plot indicates a significant correlation only between the PROLEC-S and the CONFIAS (syllable and total) for the GWI (Figure 3).

Regarding the correlation between the TRC and the CONFIAS (syllable, phoneme, and total), the scatter plot shows a significant correlation only for the GWI, although the values of the GWOI were very close to significance (Figure 4).

In order to obtain a cutoff value for the PA score so that a child's result indicates the occurrence of reading comprehension disorders, an ROC curve was created (Figure 5) that takes the TRC as the gold standard.

The point closest to the upper left corner of the ROC curve corresponds to the maximum sensitivity (0.79) and specificity (0.96) reached. The cutoff CONFIAS value corresponding to this part is 58.6. Thus, children with a CONFIAS score of 59 or higher can be classified as having appropriate performance on TRC. 


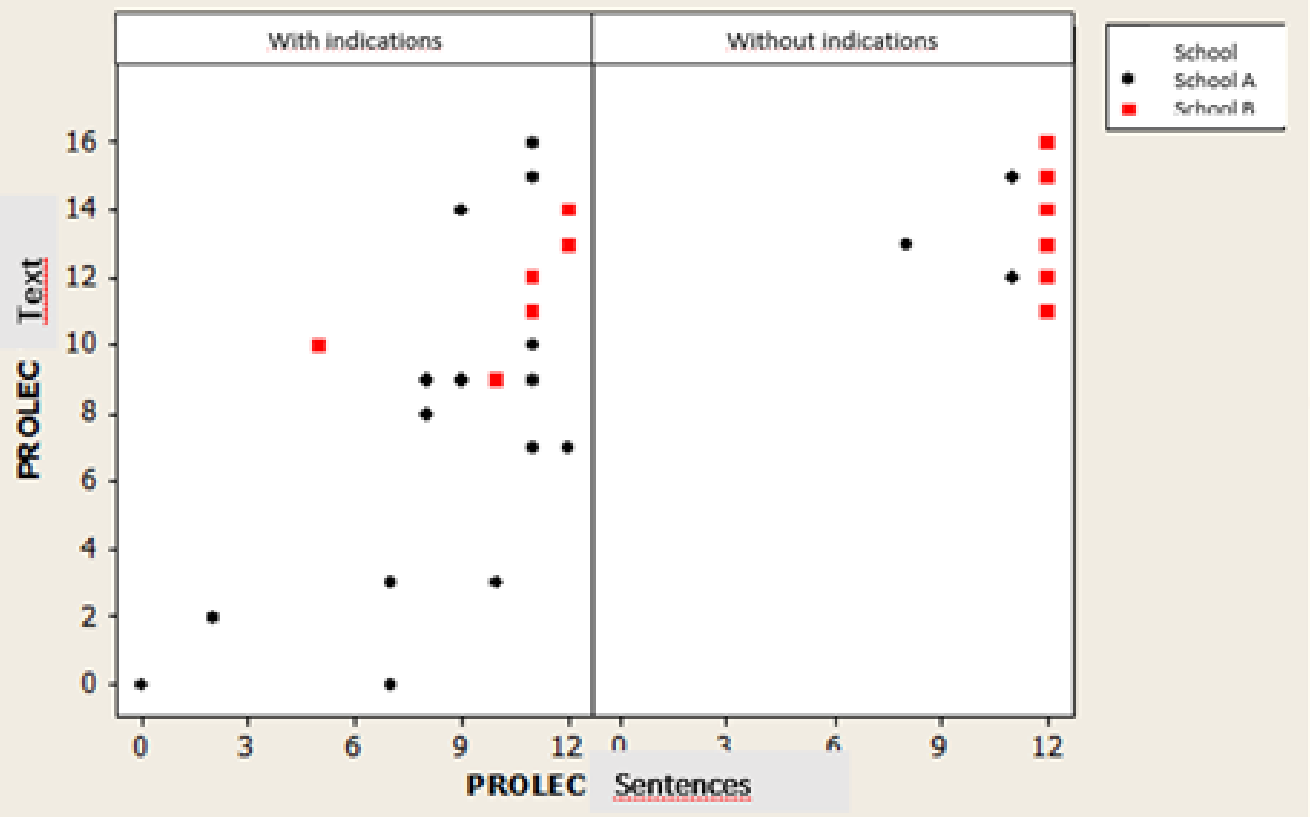

Figure 2. Scatter plot chart for PROLEC sentences and PROLEC texts of the groups with and without indications of reading and writing disorders

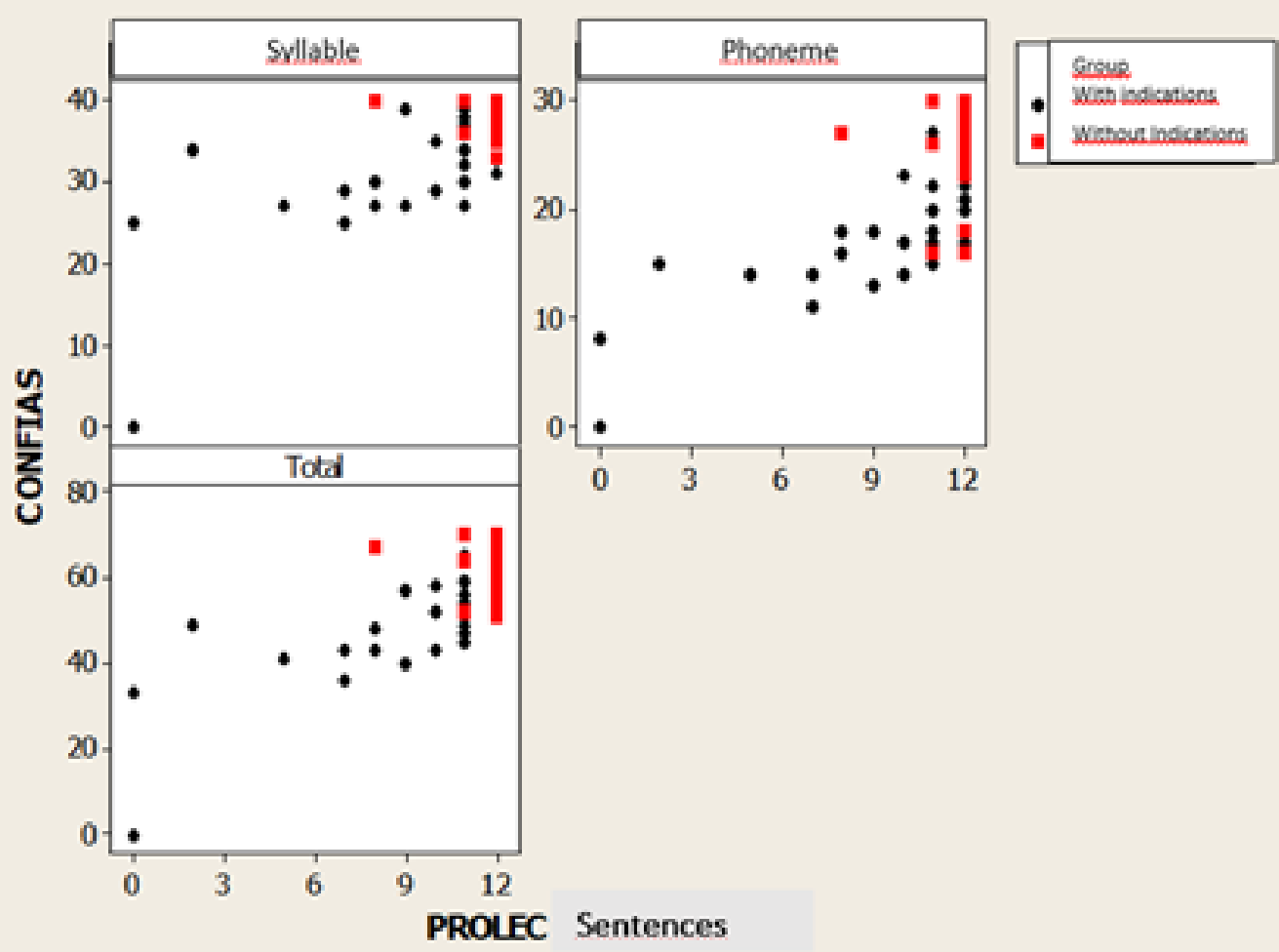

Spearman Correlation Coefficient Values:

Syllable- with indications: $r=0.53(p=0.003)$ without indications: $r=0.02(p=0.917)$

Phoneme- with indications: $r=0.67(p=0.237)$ without indications: $r=0.07(p=0.702)$

Total- with indications: $r=0.63(p<0.001)$ without indications: $r=0.02(p=0.934)$

Figure 3. Scatter plot chart of PROLEC Sentences and CONFIAS (Syllable, Phoneme, and Total) for children with and without indications of reading and writing disorders 


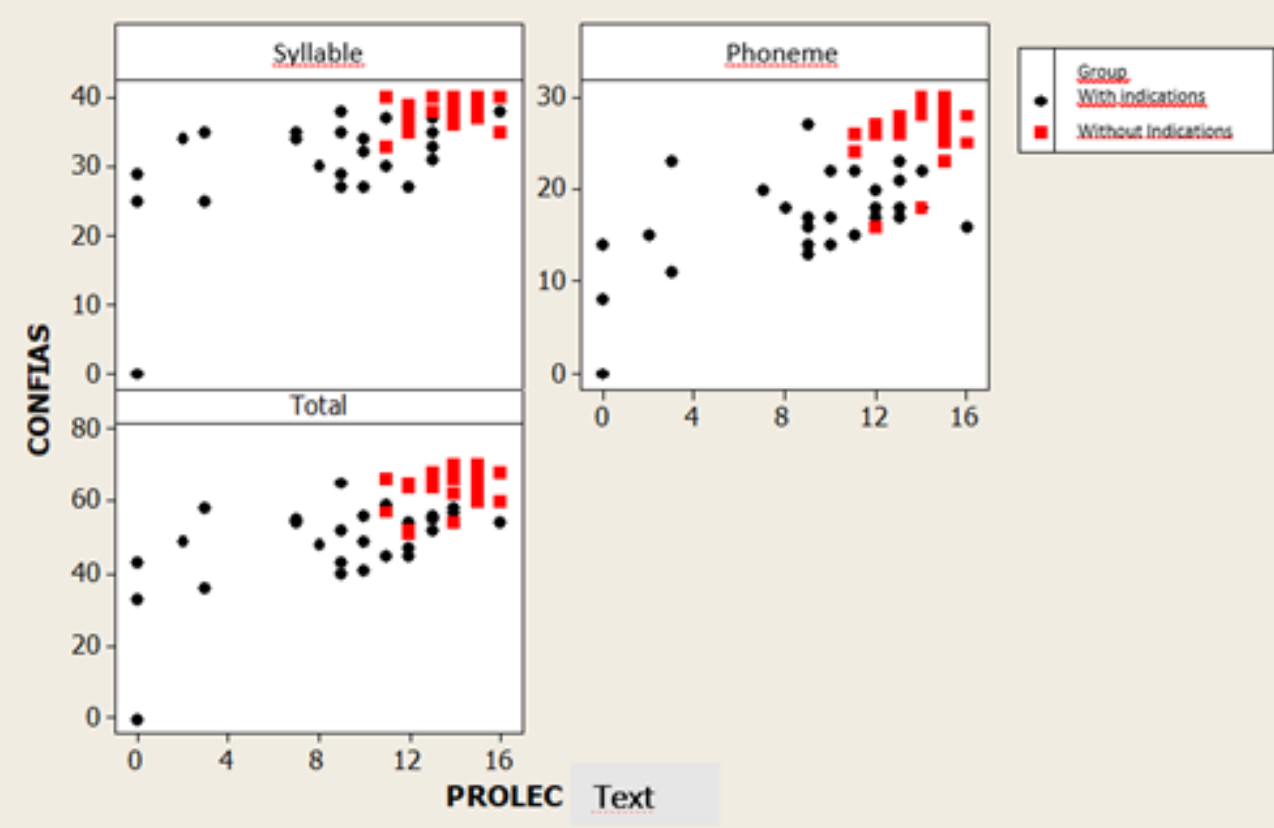

Spearman Correlation Coefficient Values:

Syllable- with indications: $r=0.54(p=0.002)$ without indications: $r=0.26(p=0.160)$

Phoneme- with indications: $r=0.45(p=0.013)$ without indications: $r=0.33(p=0.078)$

Total- with indications: $r=0.51(p<0.004)$ without indications: $r=0.35(p=0.060)$

Figure 4. Scatter plot chart for PROLEC texts and CONFIAS Syllable, Phoneme, and Total, for children with and without indications of reading and writing disorders

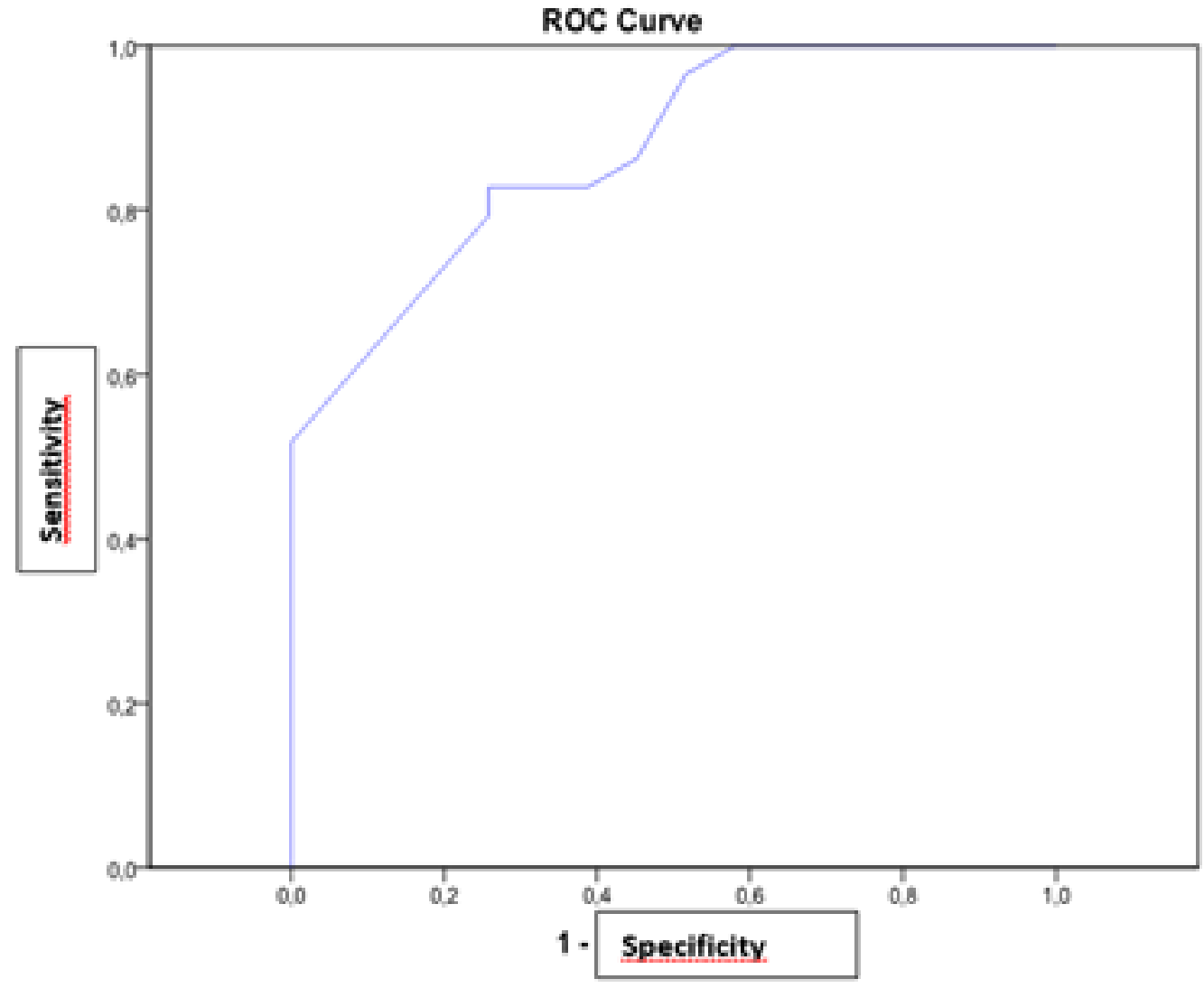

Figure 5. ROC Curve for the total CONFIAS considering PROLEC texts as the gold standard 


\section{DISCUSSION}

Regarding SRC performance, we should note the proximity in the averages between the GWI from school $B$ and the GWOI from school A, which was unexpected since the children belonged to different groups and, in the case of one of the groups, were smaller in number (Table 1). These data show a better performance by the children in school $B$, which might be related to the schools' Basic Education Development INDEX (BEDI), which differed by 1.2 in 2011. The indices for schools $A$ and $B$ were 4.7 and 5.9 , showing the better quality of education in the latter school.

We also stress that there was no significant difference between the scores of schools $A$ and $B$ for the GWOI; that is, the children from both schools obtained averages above the GWI, which has already been discussed in the literature, since students with good school performance tend to have superior reading and writing results ${ }^{3,14,16}$.

The statistical analysis also showed that the performance of most GWI students from school B was classified as "above average," while at school A only one student had an "above average" performance. This suggests that the PROLEC-S did not distinguish students with indications of reading and writing disorders at school B. A possible explanation for these results might be related to the emphasis of the teachers from the classrooms involved in the study on sentence reading comprehension.

On the other hand, we should note that in school $\mathrm{A}$, the percentage of students classified as "below average" was higher among the GWI, whereas among the GWOI only one student was "below average." On this last point, the sentence comprehension test was an efficient indicator to distinguish children with and without reading and writing disorders. Thus, one may speculate that for children with better school literacy practices and family support (school B), the sentence comprehension test might not be a sufficiently discriminating tool for children with disorders. However, among children with reduced or impaired literacy practices, that is, students with indications, the PROLEC-S was an important tool for performance differentiation.

Statistical analysis of the results obtained on the TRC test showed that the means and medians of the GWOI were higher than those of the GWI at both schools, which was already mentioned regarding the SRC, in which students without indications of disorders tend to have superior results ${ }^{3,14,16}$ (Table 2). The fact that the median of the children at school B in the GWI is closer to that for school A's GWOI shows that these students (school A) have a more variable performance, as previously discussed, since school A is located in a neighborhood with lower socioeconomic levels, and this fact might have contributed to the children's poor performance ${ }^{2,21}$.

When comparing the performance of the GWI and the GWOI from both schools, a significant difference was found between the score distributions on PROLEC-T. The results also showed that the scores for the GWI tend to be lower than in the GWOI, which means that the PROLEC-T was a good indicator for students with and without indications of reading and writing disorders regardless of school quality, unlike sentence comprehension.

The frequency and percentage distributions of PROLEC-T for the two groups showed that most students with indications were classified as "below average," while in the group without indications, most had an "above average" performance, once again showing that this test was effective in distinguishing children with and without indications regardless of their school (Table 3). Thus, the PROLEC-T text comprehension test can be used as an important indicator of possible reading and writing disorders, which was already demonstrated in a previous study ${ }^{14}$.

It is important to remember that it was expected that the reading comprehension skills of fourth grade students would already have been established, since this skill rapidly evolves during the school years, as observed in the children of this study without indications of reading and writing disorders 3 ,14,16,22,23.

The statistical data indicate a significant correlation between the PROLEC-T and PROLEC-S scores only in the GWI (Figure 4), which means that the students in this group with below-average scores on sentence reading comprehension were also below average in text reading comprehension. This result was expected, since reading comprehension involves such skills as cognition and metacognition ${ }^{17,24}$. However, sentence reading demands less metacognitive skills than does text reading ${ }^{14,17,22,24}$. Thus, for the children in this study, difficulties in simpler tasks necessarily implied difficulties in more complex tasks.

It is a fact that during the development of reading processes, students move from the word level to the sentence level, and then to the text level. One study ${ }^{25}$ pointed out that as written word comprehension performance increases, written sentence comprehension performance also increases. This is because there is 
a relationship between the reading of isolated words and reading comprehension. Similar results have been described in other studies $26-28$.

The statistical analysis also showed that there was no significant correlation between the PROLEC-S and PROLEC-T scores for the GWOI (Figure 4). That means that among children without indications of reading and writing disorders, good performance in sentence comprehension cannot be considered as an adequate text comprehension predictor. This might be due to the great ease in reading that children without reading and writing disorders demonstrated on the SRC test and to the possibility that this is not a differentiating test for children with typical development, since many national and international studies highlight that reading development occurs progressively from word to text ${ }^{14,24,25,27}$ (Figure 3).

Regarding PA, it was observed that the GWOI score was higher than for the GWI in syllables, phonemes, and overall, which corroborates findings in the literature showing higher average scores by children without indications in all PA variables ${ }^{28,29}$ (Figure 3).

When analyzing the performance of the groups in syllable, phoneme, and total CONFIAS scores, it was observed that the GWOI and GWI from both schools (A and $B$ ) had similar averages without a statistically significant difference. These data indicate that regardless of the school, the groups with and without indications showed comparable results. Thus, the groups will henceforth be referred to only as the GWOI and GWI without mentioning their schools (Figure 3 ).

The GWOI showed a superior phonological awareness performance on syllables, phonemes, and overall when compared to the GWI. In particular, the GWOI had a higher average for their performance on syllabic awareness, and this difference was statistically significant. These results indicate that syllabic awareness can be an important aspect determining children with and without reading and writing disorders (Figure 3).

The difference between the GWOI and the GWI in their performance on phonemic awareness was also significant, indicating that phonemic awareness properly distinguished children with and without indications of reading and writing disorders. Phonemic awareness is developed throughout the learning of reading and writing, and research shows that it is more related to the literacy process than syllabic awareness. Still, for phonemic awareness to develop, the development of syllabic awareness is necessary, and the child thereby advances more easily and efficiently in reading and writing ${ }^{10-12}$.

It is important to note that among the students in this study, no differences in their performances on syllabic and phonemic awareness were verified, indicating that in children with more advanced education the development of phonemic awareness tends to parallel the development of syllabic awareness. These data demonstrate the importance of this research regarding the knowledge of public school students' PA acquisition standards. Thus, it is expected that the knowledge of the sounds of the language widens and evolves to the recognition and manipulation of phonemes, unlike what happens at the beginning of the literacy process, where the performance of the syllabic awareness is superior to the phonemic awareness ${ }^{2,7,11,12,20,21,24}$.

Regarding the total PA score, the significant difference observed for the GWOI confirms other studies $^{11,21,24}$ that found a reciprocal relationship between PA and the learning of reading and writing. This, on the other hand, can be influenced by the extrinsic conditions of each child, which can also interfere with the development of $\mathrm{PA}^{12}$. This means that children's PA can be affected by what they experience, and it is common for the socially and culturally less favored to have reduced opportunities for linguistic reflection ${ }^{2,12,21}$. Such a hypothesis was confirmed when determining the worst performance by the GWI from school A, which is located in a region with inferior socioeconomic and low education levels.

The inferential analysis showed a significant correlation between TRC and PA performance for syllables and phonemes as well as overall for the GWI (Figure 4), which suggests that students with lower PA performances will show a higher impairment of text comprehension. On the other hand, PA was not the main factor for children without disorders having a good TRC performance. Taking into account that these are fourth graders and that the texts of this test are short, school time might have been an important variable affecting these children's performance on reading comprehension ${ }^{3,13,16,17,26}$.

When analyzing the data on a ROC curve, it was verified that the PA performance could be considered a predictor for TRC since the children that obtained a score of 59 or higher on CONFIAS were classified as "normal" in text comprehension, that is, as children with regular development for their level of education (Figure 5). However, those who scored 58 points or less were classified as having reading comprehension difficulties. 
The findings of this research corroborate other studies $^{3,17,26,27}$, confirming that syllabic and phonemic skills are directly and positively correlated with students' reading comprehension performance. It is important to note that the data of this research expand the knowledge of the field by showing consistent evidence that PA can be considered a predisposing factor for appropriate reading comprehension. In addition, the results indicate a minimum score on the CONFIAS test at which there will be a certain probability that the child will present a performance considered appropriate for the text comprehension test, which significantly contributes to the field of reading and writing in Brazil.

\section{CONCLUSION}

These data allow us to conclude that fourth-year elementary school students without indications of reading and writing disorders have a better performance regarding phonological awareness and sentence and text reading comprehension than do students with indications of reading and writing disorders.

In addition, the pre correlations between the phonological awareness and the text and sentence reading comprehension show the importance of meta-phonological skills, not only for the establishment of proficient reading but also for reading comprehension.

Lastly, the results show that syllabic and phonemic skills of phonological awareness are key to good performance on text and sentence reading comprehension, once the ROC Curve accurately distinguishes students with and without difficulties on text reading comprehension. Therefore, this study contributes to the literature by expanding our knowledge of the correlation between PA and reading comprehension in children with more schooling time (in the fourth grade).

\section{REFERENCES}

1. Erdogana $T$, Erdogana $O$. The determination of primary school first year students' phonological awareness skills. Procedia Soc Behav Sci. 2010;1(1):532-6.

2. Guedes MCR, Gomes CA. Consciência fonológica em períodos pré e pós-alfabetização. Cadernos de Letras da UFF - Dossiê Letras e Cognição 2010;41: 263-81.

3. Mousinho R, Correa J. Inter-relação entre processamento fonológico e compreensão leitora do $2^{\circ}$ ao $4^{\circ}$ ano do ensino fundamental: um estudo longitudinal. Rev. Psicopedag. 2010;27(82):27-35.
4. Campos AMG, Pinheiro LR, Guimaraes SRK. A consciência fonológica, a consciência lexical e o padrão de leitura de alunos com dislexia do desenvolvimento. Rev. Psicopedag. 2012;29(89):194-207.

5. Novaes CB, Mishima F, Santos PL. Treinamento breve de consciência fonológica: impacto sobre a alfabetização. Rev. Psicopedag. 2013;30(93):189-200.

6. Capellini AS, Oliveira AM, Pinheiro FH. Effectiveness of a metaphonological and reading remediation program for students with learning difficulties. Rev Soc Bras Fonoaudiol. 2011;16(2):189-97.

7. Tenório SMPCP, Ávila CRB. Phonological processing and school performance in early grades of elementary school. Rev. CEFAC. 2012;14(1):30-8.

8. Santos MTM, Befi-Lopes DM. Vocabulary, phonological awareness and rapid naming: contributions for spelling and written production. J. Soc. Bras. Fonoaudiol. 2012;24(3):269-75.

9. Capellini AS, Ciasca SM. Avaliação da consciência fonológica em crianças com distúrbio específico de leitura e escrita e distúrbio de aprendizagem. Temas Desenvolv. 2000;8(48):17-23.

10. Cavalheiro LG, Santos MS, Martinez PC. The influence of phonological awareness in reading acquisition. Rev. CEFAC. 2010;12(6):1009-16.

11. Ukrainetz TA, Nuspl JJ, Wilkerson K, Beddes SR. The effects of syllable instruction on phonemic awareness in preschoolers. Early Child Res Q. 2011;26(1):50-60.

12. Soares AJC, Cárnio MS. Phonemic awareness in students before and after language workshops. J. Soc. Bras. Fonoaudiol. 2012;24(1):69-75.

13. Andrade MWCL, Dias MGBB. Processos que levam à compreensão de textos. Psicol. estud. 2006;11(1):147-54.

14. Nalom AFO, Soares AJC, Cárnio MS. The relevance of receptive vocabulary in reading comprehension. CoDAS. 2015;27(4):333-8.

15. Brandão S, Ribeiro I. Promoção da compreensão leitora: avaliação dos resultados de um programa. In: X Congresso Internacional Galego Português de Psicopedagogia. Braga: Universidade do Minho, 2009. p. 3376-90.

16. Oliveira AM, Capellini SA. Compreensão leitora de palavras e frases: elaboração de procedimento avaliativo. Psicol. estud. 2013;18(2):293-301.

17. Rothou KM, Pedeliadu S, Sideridis GD. Predicting early reading in greek: the contribution of 
phonological awareness and non-phonological language skills. Procedia Soc Behav Sci. 2013;98(2013):1504-19.

18. Stein LM. Teste de Desempenho Escolar (TDE). São Paulo: Casa do Psicólogo, 1994.

19. Moojen S (coord). Consciência Fonológica Instrumento de Avaliação Sequencial (CONFIAS). Casa do Psicólogo, 2003.

20. Capellini SA, Oliveira AM, Cuetos F. Prolec - Provas dos Processos de Leitura: manual. Cuetos F, Rodrigues $\mathrm{B}$, Ruano E; adaptação para o português Capellini SA, Oliveira AM, Cuetos F. 1.ed.São Paulo: Casa do Psicólogo, 2010.

21. Ávila CRB. Consciência Fonológica. In: Tratado de Fonoaudiologia. Ferreira LP, Befi-Lopes DM, Limongi SCO (orgs). - 1.ed. - São Paulo: Roca, 2004. p.815-24.

22. Reynolds MR, Turek JJ. A dynamic development link between verbal comprehension - knowledge (GC) and reading comprehension: verbal comprehension-knowledge drives positive change in reading comprehension. J. Sch. Psychol. 2012;(50):841-63.

23. Williams GJ, Larkin RF. Narrative writing, reading and cognitive processes in middle childhood: What are the links? Learn Individ Differ. 2013;28:142-50.

24. Askan N, Kisac B. A descriptive study: Reading comprehension and cognitive awareness skills. Procedia Soc Behav Sci. 2009;1(1):834-7.

25. Oliveira AM, Cardoso MH, Capellini SA. Characterization of reading processes in students with dyslexia and learning disabilities. Rev. soc. bras. fonoaudiol. 2012;17(2):201-7.

26. Navas ALGP, Pinto JCBR, Dellisa PRR. Avanços no conhecimento do processamento da fluência em leitura: da palavra ao texto. Rev. Soc. Bras. Fonoaudiol. 2009;14(4):553-9.

27. Capovilla AGS, Dias NM. Desenvolvimento de estratégias de leitura no ensino fundamental e correlação com nota escolar. Psicol Rev. 2007;13(2):363-82.

28. Berninger WV, Abbott RD, Lee Swanson H, Lovitt $D$, Trivedi P, Lin SJ et al. Relationship of wordand sentence-level working memory to reading and writing in second, fourth, and sixth grade. Lang Speech Hear Serv Sch. 2010;41(2):179-93.

29. Silva MC, Ávila CRB. Influence of phonological disorders on reading and writing disabilities. Audiol. Commun. Res. 2013;18(3):203-12. 